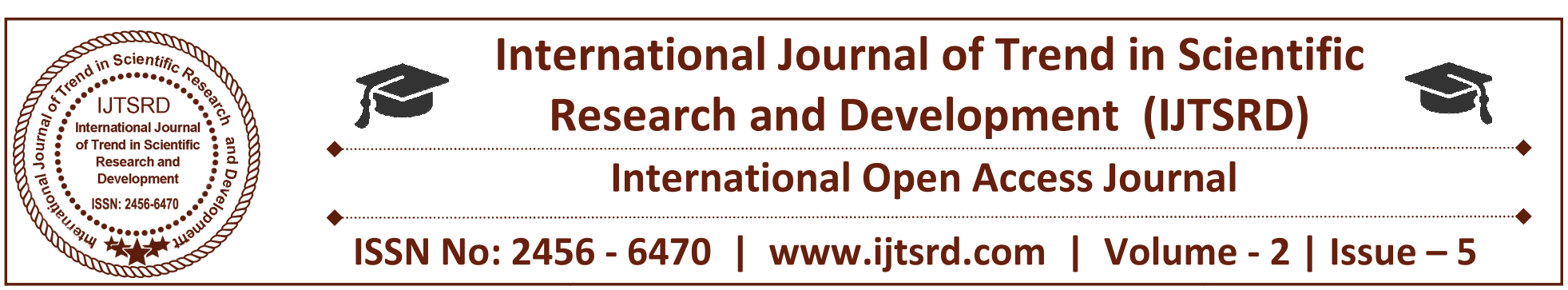

\title{
Decision Making in Waste Water Management in India
}

\author{
Kshitij Gautam \\ B.A., L.L.B. (Hons) - II Sem., Indore Institute of Law, Affiliated To DAVV and BCI, \\ Indore, Madhya Pradesh, India
}

\begin{abstract}
Lately populace is expanding to such an extent. Additionally there is huge issue of wastewater transfer. So it moves toward becoming more intricate to discover economical answer for wastewater management. It requires more procedures and propelled checking what's more, control frameworks. This paper portrays the advancement and task of a Decision Support System (DSS) for misspend water transfer administration. It utilizes the ideas, for example, components, and community setting. These depend on information structure idea. Philosophy make utilization of a typical vocabulary, which enables diverse gatherings from various space to get it what's more, speak with one another. This paper characterizes two programming module Design age module and choice guide module. Outline age module gives the no of various choices designs. It utilizes Constraint Logical Programming for desiging choices. Choice guide module enables clients to effectively choose their favored design(s) by looking at trade off between various choices produced in Design age module for that reason it utilizes esteem diagrams .Finally DSS will gives the best options which will adjust natural, monetary, and social objectives.
\end{abstract}

\section{Background}

The term "sewage treatment plant" (or "sewage treatment works" in some countries) is nowadays often replaced with the term wastewater treatment plant or wastewater treatment station. ${ }^{1}$

Sewage is produced by private, institutional, business and modern foundations. It incorporates family unit Waste fluid from toilets, showers, showers, kitchens,

\footnotetext{
${ }^{1}$ Metcalf \& Eddy, Inc. (1972). Wastewater Engineering. New York: McGraw-Hill,(12-07,10:45 P.M.)
}

and sinks depleting into sewers. In numerous zones, sewage likewise incorporates fluid waste from industry and trade. The partition and depleting of family Waste into grey water and black water is ending up more typical in the created world, with treated grey water being allowed to be utilized for watering plants or reused for flushing toilets.

Sewage may incorporate storm water spill over or urban overflow. Sewerage frameworks fit for dealing with storm water are known as consolidated sewer frameworks. This plan was basic when urban sewerage frameworks were first created, in the late nineteenth and mid twentieth centuries. Combined sewers require substantially bigger and more costly treatment offices than clean sewers. Substantial volumes of tempest spill over may overpower the sewage treatment framework, causing a spill or flood. Clean sewers are ordinarily significantly littler than consolidated sewers, and they are not intended to transport storm water. Reinforcements of crude sewage can happen if inordinate invasion/inflow (weakening by storm water as well as groundwater) is permitted into a clean sewer framework. Networks that have urbanized in the mid-twentieth century or later for the most part have constructed isolate frameworks for sewage (clean sewers) and storm water, in light of the fact that precipitation causes broadly shifting streams, decreasing sewage treatment plant proficiency.

\section{MATERIAL AND METHOD}

Presently, we should see how to expel the settling solids from the wastewater. This is accomplished through settling tank. It involves the accompanying units: sedimentation tanks: either plain or compound precipitation, portraying a septic (Imhoff) tanks and 
how this initiate the muck assimilation in. This is done with the goal to evacuate suspended mineral and natural matter from sewage after the wastewater has been subjected to go through screens and coarseness chamber. These are the units in which sedimentation is achieved. The lighter natural sewage solids, which settle in the sedimentation tanks, are named as slop, while the sewage that has been incompletely elucidated by the settling out of the solids is known as the gushing. Both slop and profluent ought to be additionally treated keeping in mind the end goal to make them stable and unobjectionable. The settlement of the solids may either be caused by gravity or by total or flocculation of sewage-particles. ${ }^{2}$ In the event that the coagulating synthetic concoctions are not included the sewage, the tanks are alluded as plain sedimentation tanks. Though, if synthetic concoctions are utilized for the motivation behind bringing the better suspended and colloidal solids into masses of extensive mass, in this way hurrying the settlement procedure, these are then known as concoction precipitation tanks. The synthetic compounds utilized are alum, lime, ferric chloride, ferric sulfate, chlorinated copper, and so forth.

\section{RESULTS AND DISCUSSIONS}

Sedimentation is expert either in flat stream or vertical-stream tanks. The previous are generally rectangular and the last round. In a rectangular tank, sewage enters consistently toward one side and goes at the opposite end, for the most part finished a weir. Muck is evacuated physically into slop processing tanks. The rubbish shaped at the surface is expelled by the mechanical scrubber with the guide of a second edge called skimmer, through a rubbish trough. On account of a round or upward-stream tank, sewage enters at the inside, ascents to be drawn off by streaming over a fringe weir masterminded at the surface. Such tanks are especially intended to make utilization of the standard of flocculation whereby, little colloidal particles are agglomerated into massive wooly masses, which are all the more effectively settled as slime on the base of the tank. Mechanical scrubbers gather the slime, concentrating it towards the middle; from it is expelled for advance treatment. The emanating streaming over the outlet weir is gathered in an outlet pipe for advance treatment.

At the point when just crude sewage is to be dealt with in these tanks, they might be by and large named as essential settling tanks or essential clarifiers. While when a sewage that has gotten auxiliary treatment, as in streaming channels or on the other hand air circulation tanks, is to be dealt with in them, at that point they might be called as auxiliary settling tanks or optional clarifiers. For the sedimentation tanks, the limit in water supply is dictated by the volume of sewage-stream and the required confinement time frame:

1. Detainment period: 1 to 3 hours. Longer periods result in higher productivity than shorter periods yet too long a period actuates septic conditions and ought to be kept away from.

2. Speed of stream: around $30 \mathrm{l} / \mathrm{sec}$.

3. Surface stacking: it might be noticed that the general scope of surface stacking between 30,000 to $50,000 \mathrm{l} / \mathrm{m} /$ day is in similarity with that utilized as a part of instance of flat stream also, vertical stream sedimentation tanks.

4. Fluid profundity of mechanically cleaned settling tanks ought not be less that $2.1 \mathrm{~m}$, also, for the last clarifier for initiated ooze, at least $2.4 \mathrm{~m}$. The second unit is portraying a septic (Imhoff) tanks. Outlined by Karl Imhoff of Germany, an Imhoff tank is an enhanced septic tank in which the approaching sewage or isn't permitted to get stirred up with the slime created. What's more, the active sewage or on the other hand profluent isn't permitted to convey with it extensive measure of the suspended issue as in the instance of an ordinary septic tank. ${ }^{3}$

\section{Currernt Condition of sewage System in India}

There are four years left for the administration focus of guaranteeing all Indians utilize toilets, yet in urban India alone, close to $30 \%$ of sewage produced by 377 million individuals moves through treatment plants. The rest is arbitrarily dumped in waterways, oceans, lakes and wells, dirtying three-fourths of the nation's water bodies, as indicated by an IndiaSpend investigation of different information sources. An expected 62,000 million liters for every day (MLD) sewage is produced in urban territories, while the treatment limit crosswise over India is just 23,277 MLD, or $37 \%$ of sewage created, as indicated by information discharged by the administration in December 2015. Additionally parsing of this information uncovers that of 816 civil sewage treatment plants (STPs) recorded crosswise over India, 522 work. In this way, of 62,000 MLD, the 
recorded limit is 23,277 MLD however close to 18,883 MLD of sewage is really treated. That implies $70 \%$ of sewage produced in urban India isn't dealt with. While 79 STPs don't work, 145 are under development and 70 are proposed, as indicated by the Central Pollution Control Board's (CPCB) Inventorization of Sewage Treatment Plants report. No change throughout the years; towns, urban communities contaminate their own particular water India's towns and urban communities sully their own particular water, with no change throughout the years. Sewage age in India from class-I urban areas (with a populace more than 100,000) and class-II towns (populace 50,000- 100,000) is assessed at 38,255 MLD, of which just 11,787 MLD (30\%) is dealt with, as per the Fecal Sludge Management report by Water Aid, a protected water and sanitation promotion, citing a 2009 CPCB report. The untreated sewage is dumped straightforwardly into water bodies, dirtying three-fourth of India's surface water assets, the FSM report said. Up to $80 \%$ of water bodies could be contaminated, the report said. Activity and upkeep of existing treatment limit is worse than average, with $39 \%$ plants not adjusting to natural guidelines for release into streams, the CPCB's 2009 report said. An expected $75 \%$ to $80 \%$ of water contamination is from residential sewage, released untreated into nearby water bodies. $^{4}$

\section{A general, developing deficiency of (working) sewage-treatment plants}

Of the 522 working STPs crosswise over India, most extreme are in the northern territory of Punjab, which has 86 . Yet, close to 38 work.

Uttar Pradesh has the most working STPs, 62, trailed by Maharashtra (60) and Karnataka (44). Around 85 million in urban India need sufficient sanitationmore than Germany's populace Around 17 million urban family units need sufficient sanitation offices in India, with 14.7 million families having no toilets, the FSM report said. On the off chance that you consider five individuals for every family that implies around 85 million people- or more than the number of inhabitants in Germany- are without satisfactory sanitation in urban India.

As far as provincial families, just $48.4 \% \quad(87.9$ million) have latrine offices as on December 7,

\footnotetext{
${ }^{4}$ Central Pollution Control Board, 12 july (10:45 P.M.)
}

2015, as indicated by an answer in the Lok Sabha, the lower place of parliament.

Around five million (7.1\%) urban family units having pit lavatories that have no pieces or are open pits, and around 900,000 toilets arrange off defecation straightforwardly into channels. Just $32.7 \%$ of urban family units that have sanitation offices utilize toilets associated with an underground sewage organize. Upwards of 30 million urban families (38.2\%), of the 79 million family units with septic tanks, have no unmistakable strategy for sewage transfer.

\section{Open defecation remains a major challenge}

Open poo remains a noteworthy test around $12.6 \%$ of urban family units poo in the open. This number is higher for ghettos, with $18.9 \%$ of families pooping in the open. Around $1.7 \%$ of families crosswise over India crap in the open in spite of having toilets, the legislature educated the Lok Sabha in an answer a month ago, in view of the National Sample Survey report $2012 .^{5}$

In Madhya Pradesh, around $22.5 \%$ urban family units poop in open spaces, trailed by Tamil Nadu (16.2\%), Uttar Pradesh (14.8\%), Gujarat (8.7\%), Maharashtra $(7.7 \%)$ and Delhi (3\%). Upwards of $55 \%$ of provincial family units poop in the open, as indicated by information tabled in the Lok Sabha on May 7, 2015. Odisha tops rundown, with $86.6 \%$ of provincial family units pooping in the open. In Kerala, close to $3.9 \%$ of family units crap in the open.

The worldwide story: Open crap has fallen considerably more than 25 years

The extent of individuals honing open poo universally has fallen nearly considerably, from $24 \%$ of every 1990 to $13 \%$ of every 2015 . Around $68 \%$ of the total populace approached enhanced sanitation offices, including flush toilets and secured lavatories, in 2015, as per the World Health Organization (WHO). Be that as it may, about 2.4 billion individuals over the world need essential sanitation offices, for example, toilets or restrooms. Of these, 946 million poop in the open, as per the WHO. Will building toilets address the issue? The jury is out The Swachh Bharat (Clean India) Mission, propelled by the National Democratic Alliance government on October 2, 2014, means to make India open-poop free by October 2, 2019. The administration intends to build 2.5 million individual

\footnotetext{
${ }^{5}$ Supra4
} 
family toilets in urban regions by 2015-16, of which 882,905 were built upto December, 2015, as per most recent information accessible. Upwards of 32,014 out of 100,000 network and open toilets have been worked under the Swachh Bharat Mission. The provincial sanitation program, in its first year, saw the development of 8.8 million toilets, against the objective of 6 million. $^{6}$

\section{Condition of Sweage Treatment in Delhi}

It is really very strange that Delhi, which is India's national Capital, one of the fastest growing metropolitan cities of the country, does not have a proper sewage disposal and drainage system. Delhi is facing severe problem of untreated sewage such that only about $55 \%$ homes in Delhi are linked to a proper sewerage and the rest of the $45 \%$ of wastes goes in to the Yamuna River directly.

Truth be told, it is extremely exceptionally pitiful to state that the dung of the useful cabinets of the cutting edge washrooms in urban Delhi are adding to the contamination of Yamuna. Notwithstanding the way that various plans and projects have been executed by the Government for sewage and wastewater treatment, these are not having the capacity to keep pace with the developing age of waste water. While there are sure segments like created and sorted out zones of Delhi which are given wastewater treatment administrations to a specific degree, the ghettos or the sloppy territories are not given any sewage treatment, the reason being they are not inside the ward of the Delhi Jal Board (DJB). Statistical data points of sewage treatment in Delhi As indicated by report distributed in 2012, just around $30 \%$ of all the sewage that comes in Delhi is dealt with. It has been evaluated that on a normal for every day 3296 million liters of sewage is dumped in the Yamuna. Every day, Delhi creates around 600 million gallons of sewage, however the sewage treatment plants (STPs) set up in Delhi have an ability to treat just 512.4 million gallons of waste. On November 11, 2012, the Supreme Court had pronounced that all parameters of water nature of Yamuna pretty much are like a deplete. Additionally, the national Capital does not have an appropriate seepage framework and sewer lines. ${ }^{7}$ There are 30 sewage treatment plants situated at 17 areas in Delhi, out of which just two are running inside as far as

\footnotetext{
${ }^{6}$ IBID

${ }^{7}$ Rumani Saikia Phukan, https://www.mapsofindia.com/myindia/government/sewage-problem-threatens-to-consumenational-capital
}

possible, 20 are running under limit, five are running over limit and three are non-practical.

Result of sewage issues Dishonourable and insufficient sewage treatment have affected nature and the subjects of Delhi from numerous points of view:

$>$ Breaking down septic frameworks have brought about sullying of well water, ground water, waterway water and making dangers general wellbeing

$>$ Untreated and open seepages have created helpful rearing for mosquitoes, flies, rodents, creepy crawlies and different sicknesses conveying vectors.

Untreated sewage have prompted stinking and foul smell Guide physical introduction to wastewater for individuals showering and washing garments and utensils

Poisonous sustenance cultivating has expanded around the Yamuna stream because of uncalled for sewage treatment, prompting different illnesses like as regurgitating, gastroenteritis, loose bowels, blood disease, lack of hydration, kidney brokenness and urinary contamination.

The poisons have contaminated the ground water and soil. ${ }^{8}$

Who is in charge of the wastewater and sewage treatment in Delhi?

The Delhi Jal Board (DJB) is the expert in charge of arranging, execution, planning of water supply and wastewater and sewage administration inside its purview in the National Capital Territory of Delhi. According to DJB, the sewerage framework accessible in different classifications are as per the following:
Arranged settlements (just 40\%)
Unapproved regularized settlements
Resettlement settlements
$>$ Urban towns
$>$ Rustic towns, unapproved states and JJ Cluster

\section{Significant issues in sewage treatment}

$>$ Delhi's populace is becoming regular and this is one prime reason that influences the sewerage administrations accessible to its subjects.

$>$ The majority of treatment plants don't perform adequately because of operational issues.

$>$ The present limit of the STPs is underutilized by virtue of lack in the gathering framework. 
$>$ The huge system of sewers and depletes in the city is exceptionally old and the majority of them are little and furthermore in harmed condition.

$>$ Low stream of sewage to STPs

$>$ No appropriate sewage administration and arranging

$>$ Delhi Jal Board had not arranged any "appropriate and point of view" get ready for sewage treatment.

$>$ Surprising expense treatments however ease recuperation that powers DJB to rely upon intemperate credit assistance from the Government.

\section{Other reason}

$>$ Absence of foundation

$>$ Frail budgetary base

$>$ Defilement

$>$ No co-ordinating body

$>$ Absence of political will

$>$ Absence of responsibility and so forth.

\section{What is the Solution? Decide on decentralized little scale sewage treatment frameworks}

According to a report by the Delhi Government of 2013, in the vicinity of 2007 and 2012, Rs 3,132.50 crore have been spent in sewage treatment programs in the Capital city. In Delhi today, there is a shortage of $9,500 \mathrm{~km}$ sewage pipeline and a venture of Rs 25,000 crore is required to manufacture these sewage pipelines. The DJB has spent around 1,634.18 crore in 2011-12 on the tasks, support and development of STPs however of no applicable result.

The Government and the DJB ought to consider decentralizing its sewage treatment framework. Decentralized sewage treatment otherwise called "Nearby wastewater treatment framework" is one that treats releases, sewages, wastewater at the area itself where the sewage is produced. For instance, regardless we have the basic arrangement of septic tanks and drain fields serving single homes in different towns and towns in India. Rather than sending the losses into an immense STP in a specific area, the water is dealt with and come back to the ground on a similar zone.

A concentrated STP gathers sewage from different areas of the city and after that treat it. Be that as it may, this framework requires a lot of capital speculation and is profoundly work serious which require normal support and make utilization of a lot of power and much of the time is non-practical. ${ }^{9}$

That is the reason, selecting of privatization or decentralization of sewage water treatment is a decent arrangement. The occupant welfare affiliations ought to be made in charge of task and support of the decentralized sewage treatment. Truth be told, numerous land engineers in Delhi have officially actualized this in the different townships and flat social orders situated in Delhi. Decentralized little scale sewage treatment frameworks are a productive method for arranging and redesigning Delhi's urban condition to a maintainable level.

\section{CONCLUSION}

Considering multiple factors affecting the construction of sewage treatment plant, this paper

developed a survey on only Delhi National Capital because it was very tough for a researcher to show the fact or data for whole India.

In this paper researcher emphasize only on the condition of Delhi and its solution to overcome the problem face by the people of Delhi in the name sewage management.

In this paper there are also some solution given by the researcher to overcome from our disastrous water management. 